\title{
Bridge Builders to Health Equity: The High School Community Health Worker Training Program
}

\author{
Arletha D. Williams-Livingston, PhD, MPH, MBA ${ }^{1}$, Christopher E. Ervin, $\mathrm{MD}^{1}$, and Gail G. McCray, MA, MCHES \\ ${ }^{1}$ Morehouse School of Medicine, Department of Family Medicine and ${ }^{2}$ Morehouse School of Medicine, Department of Community Health and \\ Preventative Medicine
}

Corresponding Author: Arletha W. Livingston, PhD, MPH, MBA • Morehouse School of Medicine, Department of Family Medicine • 1513 E. Cleveland Avenue, Bldg. 100A Suite 300 East Point, Georgia 30344 • Telephone: (404) 756-1221 • Email: awlivingston@msm.edu

\begin{abstract}
Background: During the summers of 2016-2019, Morehouse School of Medicine (MSM) with the support of community partners, developed, piloted and implemented an innovative Community Health Worker Training Program for High School students (HSCHW). Training high school community health workers can impact health and social disparities in underserved populations and demonstrates the pipeline of future workers in community health and other health careers. The program has achieved promising outcomes, and access to the program model has been requested by many universities and community-based organizations.
\end{abstract}

Method: The HSCHW training consists of summer classroom instruction, field instruction and monthly continuing education during the school year. The students are trained in CHW core competencies through a combination of online curriculum, interactive classroom experiences, and field activities provided by community partners, multidisciplinary MSM clinical instructors, and graduate student interns.

Results: 77 high school students from metropolitan Atlanta High Schools and rural Columbus, GA have been trained as CHWs in the HSCHW program. Students are ages 15-18 and are rising sophomores to recent high school graduates. All participants (100\%) were from economically disadvantaged communities. Sixteen school-based and community-based health improvement projects have been developed and implemented by teams of trained HSCHWs. Additionally, over 300 individuals (family and community members) received monthly health monitoring by trained HSCHWs.

Conclusions: Overall, the HSCHW program models the engagement of community partners in translational educational initiatives to support community transformation. It can be a giant leap toward improved population health and achieving health equity in underserved communities. It has had a tremendous impact on the youth themselves, their families, and the communities in which they live. In communities with disparate prevalence of chronic disease and unhealthy behaviors, early exposure may mitigate exacerbation or early onset of disease among the participants and their families. High School Community Health Workers are bridges to health equity.

Keywords: Pipeline programs, community health workers, community engagement, health equity, HealthTech, population health

\section{INTRODUCTION}

According to the American Public Health Association, community health workers (CHWs) are frontline public health workers who are trusted members of and/or have an unusually close understanding of the community served (APHA, 2010). This trusting relationship enables CHWs to serve as liaisons, links, or intermediaries between health and social services and the community to facilitate access to services and improve the quality and cultural competence of service delivery. CHWs also build individual and community capacity by increasing health knowledge and self-sufficiency through a range of activities such as outreach, community education, informal counseling, social support and advocacy (APHA, 2010).

Morehouse School of Medicine (MSM) has trained $\mathrm{CHWs}$ /promotores/lay navigators for more than 15 years. The initial MSM training curriculum was developed in collaboration with the American Cancer Society Southeast Region and the Georgia Department of Public Health. (MSM, 2000) To date, MSM has trained more than 350 CHWs to work in a variety of settings (community, clinics, academia, research, etc.) and in many healthcare areas, such as diabetes, cancer control, reducing emergency room visits from "frequent flyers," and increasing the number of 
children and adults with insurance (Morehouse School of Medicine [MSM], 2015).

According to the World Health Organization (WHO), there will be a worldwide shortage of approximately 12.9 million healthcare workers by 2035. The WHO supports the belief that CHWs can help fill that gap. Two of the main recommendations from the WHO to address this shortage are "maximizing the role of mid-level and community health workers to make frontline health services more accessible and acceptable" and "retention of health workers in countries where deficits are most acute and greater balancing of the distribution of health workers geographically" (World Health Organization, 2013). One program in which MSM is addressing the shortage is to create a sustainable model of $\mathrm{CHW}$ training with a population that can be trained easily and that is rooted in the community.

During the four summers of 2016-2019, MSM, with the support of the Atlanta Regional Collaborative for Healthcare Improvement (ARCHI), developed, piloted, and implemented an innovative high school community health worker (HSCHW) training program. The ARCHI workgroup identified several gaps in health status in several zip codes, if left unaddressed would have significant health, economic, and social impact on the community (ARCHI, 2017). This program was created as an opportunity to address known health status inequities in the southwest area zip codes of 30331, 30337, 30344, 30349, and 30354 of metropolitan Atlanta with this innovation. The idea was that these students could provide vital health information to the underserved community and school population. Through the summer of 2019, MSM has trained 77 high school students from 24 metro-Atlanta High Schools and one rural high school in Columbus, GA. In 2019, rural Georgia was included in order to pilot the program in such underserved communities for the Georgia Department of Public Health (Ga DPH). Students are ages 15-18, rising sophomores to recent high school graduates. This article addresses how using an innovative multidisciplinary team approach to training HSCHWs impacts health and social disparities in underserved populations in urban Metro Atlanta and demonstrates an additional way to develop a pipeline of potential workers in community health and other health careers.

The rationale for the development of this training program includes the mission of MSM, which is to "improve the health and well-being of individuals and communities; increase the diversity of the health professional and scientific workforce; and address primary health care through programs in education, research and service with emphasis on people of color and the underserved urban and rural populations in Georgia, the nation and the world." Its vision is to "lead the creation and advancement of health equity" (MSM, 2015).
MSM places heavy emphasis on the development of strategic partnerships to achieve its mission and vision. One of those strategic community partnerships is with ARCHI (Atlanta Regional Collaborative for Health Improvement). ARCHI's mission is to "engage public, private and community partners to improve healthcare and foster health-promoting social, economic and educational environments" (ARCHI, 2017). The HSCHW program developer, served on the ARCHI Tri-Cities Stewardship Committee and as co-chair of the Care-Coordination Subcommittee. In April 2016, the program developer presented the idea for the program to the ARCHI Tri-Cities Stewardship Committee. The committee pledged to support (and later helped to fund) the pilot project as a part of its ReThink Health Atlanta initiative to transform health indicators in Atlanta's underserved communities by 2040 (ARCHI, 2017). Following the pilot project in 2016, other partners have included the Georgia Department of Public Health, Fulton-Dekalb Hospital Authority, The United Health Foundation, United Way of Greater Atlanta, WellCare, The Andrew Young YMCA, Georgia State University Health Policy Center, Grady Healthcare, and Piedmont Health.

The socioeconomic profile of the Southwest Atlanta/South Fulton region further supports the rationale for the implementation of the HSCHW program. This underserved area of metro Atlanta is historically known for disparate health outcomes, poverty, and crime. Studies point to the effectiveness of community-driven interventions for community improvement, including health; community engagement is key (Wallerstein et al., 2015; Akintobi et al., 2016).

Another motivation for the development of the HSCHW program includes health sector career projections. Indeed, there is a shortage of trained health professionals in underserved communities (Grover, 2016). This program seeks to increase the number of health professionals from this community by providing a unique exposure to health education and health careers for local students.

Understanding the confluence of social determinants of health and health disparities as barriers to health equity, this program is a much-needed sustainable social innovation that addresses needed pipeline experiences for underserved populations. The content includes opportunities for students to learn more about population health, data management, human-centered design of community health projects, self-care management, and teen health.

\section{Literature Review}

An examination of CHW programs in the United States and internationally supports the intentions of the training: improving healthy behaviors in under resourced communities in the south Metro Atlanta area, fostering care coordination for those family and community members with 
chronic disease, and serving as an entry point for students who have an interest in health careers.

\section{Community Health Workers}

One of the challenges in training high school students to be CHWs is one faced by any training program for CHWs. CHWs are lay members of the community who themselves have had both positive and negative experiences in the healthcare system. In addition, CHWs are a relatively new addition to medical care teams, and their integration into the holistic continuum of care is still being developed. Thus, an effort we made to instill within the program elements that will help ensure that our young CHWs have a successful and rewarding experience. For example, the curriculum supports the understanding of the healthcare continuum. Students participate in classroom exercises where they form teams and identify a health issue; the team researches the health issue, identifies barriers to control, then develops solutions and discusses the strengths and weaknesses of those solutions. The participants also engage in experiential learning opportunities in community settings such as hospitals, clinics, schools, community-based organizations and community centers, with hands-on experiences appropriate for that setting (e.g., art therapy at a mental health counseling agency). A well-designed program can lead to scalable patient-centered care interventions led by CHWs that allow patients to focus on the chronic condition of their choice, motivate the patient for health behavior change, and provide additional support for those patients connected to primary care (Kangovi et al., 2014).

One motivating factor for CHWs is being an asset to the community with both an enhanced status and a positive impact among peers and family (Brunie et al., 2014). Another key positive factor for training CHWs is the opportunity to learn new skills and receive training across different areas and disease states (Brunie et al., 2014; Tilahun et al., 2017). During the school year there are opportunities for the trained CHWs to receive refresher courses for the skills the students learned during the initial coursework and those skills will be put to use with a community monitoring program and various community events.

Another challenge that is faced when training high school CHWs is transportation. The desire to serve members of the community has been often hampered by the ability to reach them. Student participants receive MARTA (Public transportation Metropolitan Atlanta Rapid Transit System) cards that allow them to attend the program and to get to community monitoring sites. Still another challenge that we may have to face as the program expands is integration into the larger healthcare system, where the CHW is seen as a beneficial and necessary member of the team (Brunie et al., 2014). Ideally, all individuals trained as CHWs would receive compensation for their efforts. Still, beyond compensation, it is equally important that entities recognize and reward the intrinsic motivations to become a CHW and ensure the extrinsic factors of recognition. To support the $\mathrm{CHWs}$ ' intrinsic and extrinsic motivation factors, we need to ensure that necessary resources and effective management are integrated into any $\mathrm{CHW}$ training program (Zulu et al., 2014).

\section{Community/Health Impacts}

The reason for the increased advocacy and the training and deploying of well-trained and motivated CHWs is the positive impact they can have on their family, the community, and medical care providers. CHWs have been shown to be effective in assisting their clients to reduce their hemoglobin A1C levels (HgbA1C) and improve diabetes management self-efficacy (Murayama et al., 2014; Kanea et al., 2016). For communities with a known high burden of chronic disease with residents who are not in care, CHWs may be an effective outreach and referral team (Levitt et al., 2015). CHWs could have an impact beyond the individual, working with families, by employing high-frequency home-based interventions to assist in managing their chronic health problems (Martin et al., 2016). This would allow CHWs to reach populations who are not able to or would not seek care by traditional means. This would also allow for earlier identification, diagnosis, and treatment initiation, and follow-up, and thus better health outcomes. Another study revealed that CHWs were a cost-effective approach to deliver evidence-based health promotion and education (Galiatsatos et al., 2016). In addition to the direct health and disease management impact, other areas of concern are the macro- and micro-economic impacts of using CHWs. Recent study analysis has had mixed outcomes due to different types of programs/CHW utilization. Yet, the overall trend indicates improved health outcomes with more effective (even if increased) healthcare utilization (Smith et al., 2017; Jack et al., 2017; Seidman and Atun, 2017), and well-designed programs generate positive return on investment through capture-reinvest models (Morgan et al., 2017).

\section{High School Health Career Programs}

Minority populations in the United States (identified as Black, Hispanic, Asian, American Indian/Native Alaskan, Native Hawaiian/Pacific Islander, and multiracial) have been significantly underrepresented in health careers, particularly those from low socioeconomic backgrounds. Although these minority groups make up about 35\% (Hispanics, 16.1\%; Blacks, 11.6\%) of the U.S. workforce, they are underrepresented in many of the health fields compared to Whites. In specific occupations, these differences are markedly disparate: physicians (Whites, 67.0\%; Blacks, 4.8\%; Hispanics, 6.3\%), dentists (Whites, $74.8 \%$; Blacks, 3.0\%; Hispanics, 6.1\%), pharmacists (Whites, 70.4\%; Blacks, 5.9\%; Hispanics, 3.7\%), registered nurses (Whites, 73.5\%; Blacks, 10.4\%; Hispanics, 5.7\%), diagnostic technicians (Whites, 75.7\%; Blacks, 7.8\%; 
Hispanics, 9.6\%), and laboratory technicians (Whites, 62.0\%; Blacks, 13.7\%; Hispanics, 9.4\%) (Health Resources and Services Administration (HRSA), 2017). This data influenced the decision to focus our recruitment efforts on high schools with primarily Black and Hispanic students who might have limited opportunities for exposure to health careers.

Along with factors such as academic performance and the cost of pursuing these careers, intrinsic and extrinsic factors also impact high school students' career decision-making processes. Extrinsic factors such as knowledge about the range of health careers, stress in pursuing health careers, and having family and community support are more obvious (Rashied-Henry et al., 2012). Intrinsic motivation is also a key, if not a primary factor, in high school students from low socioeconomic backgrounds (Boekloo et al., 2015) suggesting that the desired intrinsic characteristics included wanting to (a) develop ways of improving people's health, (b) answer questions about health, (c) help one's racial/ethnic group make valuable contributions to society, (d) care for people, (e) collect information about people's health, and (f) analyze information about people's health (Boekeloo, et al.). Thus, the HSCHW program seeks to address both extrinsic and intrinsic factors when identifying high school students who would be ideal to train as CHWs.

Engaging the community stakeholders is vital to both the recruitment and training of the high school students. It is also vitally important to use both formal and informal networks (Lauver et al., 2011). We worked with teachers, counselors, and community-based organizations to identify students who had expressed interest in health either as a potential career or as result of their own or family members' experiences with chronic illness. In addition, working with school- and community-based partners helped support the program in promoting the training activities and the students' service projects. This fostered an environment to not only promote the program but demonstrate the ability of students to participate in community-participatory strategies to reduce health disparities and improve health outcomes. The latter is a key program component designed to promote health careers as an avenue to work in their communities (Rashied-Henry, et al., 2012).

\section{METHODS}

The methods employed to develop, implement, and evaluate the program are discussed in this section of the article. These methods include recruitment and orientation of participants, training, program implementation, partnership development and fundraising.

The goal of the HSCHW program is to engage high school students from underserved communities to find innovative ways to impact health outcomes for those communities. The objectives of the program are to:
- increase the number of trained student CHWs to assist with community health programs in underserved communities;

- provide a health careers pipeline program and mentorship for underserved students;

- $\quad$ support and promote the CHW field;

- promote health education and improve health literacy in schools and communities; and

- assist trained HSCHWs with the design and implementation of school- and community-based health initiatives.

- provide health monitoring and health literacy activities to students' family members and community members (MSM Pipeline, 2017).

\section{Participants}

The target audience for the HSCHW program is rising 10th-12th grade students and recent graduates of all metro-Atlanta area schools. In addition, high school students in Columbus, GA are welcome to apply to the rural program. The initial student participants, family, and community residents of the pilot project were all from underserved populations in identified zip codes by the ARCHI Tri-Cities Stewardship Committee.

In 2016, the state of Georgia ranked 41st in America's Health Rankings provided by the United Health Foundation (United Health Foundation, 2019) . Our target for the pilot project in 2016 was in Fulton County, the most populous county in Georgia according to the 2010 U.S. census. The community served by the program was zip code 30344 and surrounding areas demarcated by zip codes 30331, 30318, 30311, 30349, 30315, 30354, and 30310, as well as surrounding designated neighborhood planning units (NPUs) Z, X, S, and R in the City of Atlanta. We recruited from four high schools in these zip codes of high morbidity and mortality from chronic diseases (ARCHI, 2017) and trained 13 students during the first year of the program. In 2018 and 2019 we added five schools. Starting in 2019, we opened the program to all areas and schools of Metro-Atlanta and one high school in the more rural area of the state, in Columbus, GA. The reason for expansion to Columbus was 2-fold. The Georgia Dept of Public Health, recognizing the value of the program, wanted to pilot it in a rural community to assess feasibility and value of the program and to promote it to other health districts. Second, MSM wanted to assess program implementation in rural areas and assess the virtual learning aspects in an underserved community with limited resources.

A 2013 community needs assessment was conducted by the MSM Prevention Research Center (MSM, Prevention Research Center, 2013). The 2013 assessment of NPUs including and immediately surrounding zip code 30344 identified diabetes and related risk factors as high priorities for this region. Limited community health programs, education, and training in how to develop healthy diets and 
increase physical activity in ways that were realistic and relevant in the community context were gaps contributing to this need. Mental health counseling services were also critical, due to high rates of stress, anxiety, and depression. This information also points to social determinants that lead to decreased life chances for residents.

Other issues facing zip code 30344 and surrounding areas are the barriers to accessing health information knowledge and tools for managing and improving health (MSM-PRC, 2013). A study from the Pew Internet and American Life Project reported that "wealth and information seeking go hand in hand" (Fox and Duggan, 2013). Only 54\% of those making under $\$ 30,000$ per year search for medical information online, compared with $80 \%$ of those who make $\$ 75,000$ or more per year. People with chronic conditions are less likely to access the internet (52\%), compared with $81 \%$ of those without chronic illness. Minorities and the underserved population are even less likely to access health information (30\%) (Fox and Duggan, 2013). Along with addressing those health disparities listed in the community needs assessment, this project also sought to address health information gaps for the population of interest.

\section{Recruitment, Community Outreach, and Student Selection}

The program is implemented annually. Applications are open beginning on January 1st of each year. Outreach to local schools and communities is ongoing; however, during January-March, outreach events are planned at specific schools and community events. Participants are selected through a community-based review panel in April, and participants are notified of their acceptance by May 1 .

Students are recruited through existing school and community networks and partnerships. A stakeholder planning meeting is held every January. Partnering organizations and those organizations interested in participating are invited to the meeting. School and community contacts distribute flyers encouraging students to apply. Students complete applications through Google Docs and submit their transcripts and a letter of recommendation from a science-based teacher, guidance counselor or principal.

Students are selected by a team from MSM, community-based organizations such as ARCHI, MSM Master of Public Health Program interns and representatives from the current cohort of high school student participants. A selection rubric was developed in Year 1. The selection committee reviews student applications, required essays, commitment to community health, transcripts, and teacher recommendations as well as conducts short interviews with applicants using the rubric. The selection statistics are as follows:

- Cohort 1 (2016): 17 students applied, 13 accepted.
- Cohort 2 (2017): 54 students applied, 20 accepted (plus 6 peer mentors).

- Cohort 3 (2018): 36 students applied, 30 accepted

- Cohort 4 (2019): 52 applied, 23 accepted

\section{Curriculum}

\section{Summer Intensive Training}

The MSM HSCHW training is 266 hours total: 4 weeks (160 hours) of classroom instruction with core competencies/skills, followed by 2 weeks ( 70 hours) of field instruction (summer intensive) and additional hours of monthly continuing education (school year). The summer intensive training is held every weekday from 8:30 a.m. to 4:30 p.m. during July and early August.

During the summer intensive training part of the program, students are trained in core competencies via interactive classroom and field activities provided by community partners, MSM clinical instructors, and graduate student interns (see Table 1 in the Appendix). In 2017-18, an online curriculum was developed using the learning management platform, Canvas. The interactive online training consists of 18 modules covering community health worker core competencies, focusing on supporting students' attainment of critical thinking, decision making and communication skills. Each module, designed for the young learner, consists of a welcome video, pre-learning quiz, readings, activities and assignments and a post-learning quiz. Students are tasked with creating videos, presentations and interacting with other students and community members as part of their training.

Although this particular training has been adapted to teen participants, these core competencies are aligned with core competencies for adult CHWs as supported by the American Public Health Association (APHA, 2017) Students are paid a stipend of $\$ 1000$ ( $\$ 500$ after the summer training in August, $\$ 250$ in December and $\$ 250$ in May) for completing the intensive summer training, completing monthly monitoring activities and implementing their community projects. There is also a graduation in which community and family members are invited to participate in interactive health-related activities and watch the student participants present their community project ideas in a Shark Tank format. All participant groups receive some increment of funding towards the implementation of their community projects, with the winning group receiving the largest amount.

\section{School Year Program}

During the school year (September-May), students meet monthly on a Saturday in person 9:30 am-1:30 pm to receive educational booster sessions, discuss family/community monitoring activities, and work on the implementation of their community project. Students 
participate in additional hours of continuing education opportunities throughout the school year. Continuing education is conducted online monthly via virtual meeting platform, with quarterly in-person sessions over 12 months; it consists of both new information and reinforcement of previous instruction. Students use their provided iPads to connect to the monthly meeting; the facilitator talks to the students about the monthly data monitoring and completes booster sessions of information, depending on what the monitoring data analysis is showing that month. For example, data might indicate that many people with diabetes participating in monthly monitoring by the program did not adhere to their diet and exercise plans. The facilitator discusses diabetes as a chronic disease and what students can do to motivate their family and community members to stick to their diet and exercise programs.

\section{Community Health Projects}

During the summer training, students work in groups to brainstorm and develop a community- or school-based health project to be implemented during the school year in conjunction with local community-based organizations and school partners. During the quarterly in-person sessions, students receive training in human-centered design principles. "Human-centered design is a creative approach to problem solving and the backbone of our work at IDEO.org. It's a process that starts with the people for whom you are designing and ends with new solutions that are tailor made to suit their needs (Design Kit, 2017)." The student groups are guided through the inspiration, ideation, and implementation phases as well as sustainability planning. The students are supported through the project implementation and are assisted with report writing. The student community projects are implemented with kick-offs scheduled for the late winter or early spring (February-April) each year. Sixteen school-based and community-based health improvement projects have been developed and implemented by teams of trained HSCHWs.

\section{Family/Community Monitoring}

In addition, there is a required family/community health monitoring component. The HSCHWs are named as the "chief medical officers" of their family. They are considered a first line of defense, responsible for collecting and monitoring the family members' vital signs, ensuring compliance with physicians' orders, and encouraging the patient to sustain his/her wellness. Students are assigned to monitor five family members plus themselves (six people total per month), collect data via iPad utilizing a encrypted HIPAA compliant platform (i.e. Epi Info, RedCap), and report the data monthly to the graduate students' data analyst. (Privacy and confidentiality are maintained via de-identified data and secure data transfer mechanisms.)

Multiple stakeholders can benefit from the program: the family, with improved overall health; insurers, with fewer member emergency room visits and hospital stays; providers, with fewer readmissions because of noncompliance; and the trained students preparing for a career in the health sector. The goals of the monitoring portion are to support wellness-centered student learning and provide health monitoring and health literacy activities for students and families.

At the end of the program year in May, the students have a close-out session where they discuss how they will use their newly acquired CHW certification and how they will continue to support family and community and sustain their community health projects.

The HSCHW certification program includes:

- Instruction and materials

- Classroom and field training

○ Continuing education (monthly and quarterly)

○ Three CHW textbooks, info binder, access to learning management system (Canvas)

- Equipment

○ iPad, blood pressure monitoring equipment, and portable scale

- Two polo shirts, book bag

- MARTA cards (transportation), training stipend, quarterly monitoring stipend

- CPR certification, competency exam

- Job training and placement assistance (for high school graduates)

- Ongoing community/school projects

- $\mathrm{CHW}$ training completion certificate

\section{RESULTS}

\section{Student Learning Outcomes}

The student learning outcomes are undergirded by the overall program objectives: improving healthy behaviors in under resourced communities in the south Metro Atlanta area, fostering care coordination for family and community members with chronic disease, and serving as an entry point for students who have an interest in health careers. Student outcomes are grouped into short-term and long-term outcomes. The short-term student outcomes are evaluated through participation in the intensive summer training; the long-term outcomes are evaluated through student participation in the school-year program and beyond.

Short-term outcome metrics that are evaluated include daily attendance, student daily writing reflections, observations of student learning, training satisfaction surveys, and demonstration/utilization of skills in experiential activities. The core competencies (Table 1) provide a framework for classroom and field instruction; however, students must be able to demonstrate the skills associated with the core competencies. For example, when learning about chronic diseases, students must be able to take vital signs, ask 
patients questions about diabetic care (motivational interviewing), provide accurate health information, and so on. In short, students must be able to apply skills learned as a preparation for the long-term school-year activities when those skills will be used in monitoring activities and community health projects.

Long-term outcomes are evaluated via the school-year program, which includes community health project implementation, family monitoring activities, continued student involvement with the program as peer mentors, and student employment/entrance to college beyond the program. The ability to monitor family members using technology and guide family members in health plan and reporting data, hone skills and receive guidance with barriers along the way and help them be more comfortable while continuing to apply their skills are all important aspects of building student confidence. Similar to an internship, this program allows students to develop skills that they can continue to apply beyond the program, setting them up for whatever they desire to do beyond high school: the military, college, or a health career. Three high school graduates (of the 13) from the first year all have health-related careers (still ongoing). One of the students has joined the Army and is interested in being a surgical tech, another was trained as a doula (assists women during childbirth and supports the mother and baby after the child is born), and the third was hired as a full-time CHW by MSM.

As stated above, with both short-term and long-term outcomes, the ability for students to demonstrate what they have learned requires experiential activities and skill-based demonstration. The student learning outcomes evaluation is based on how the curriculum, specifically the core competencies, is translated to skill-based activities. Table 2 (Appendix) highlights the translation of program core competency skills into experiential activities.

Table 3

Outcomes (2016-2019)

\begin{tabular}{|l|l|l|l|l|}
\hline Cohort \# & $\begin{array}{l}\text { \# of students applied to } \\
\text { program }\end{array}$ & \#selected & \#Enrolled & $\begin{array}{l}\text { \#completed the } \\
\text { program/\% }\end{array}$ \\
\hline Cohort 1 (2016) & 17 & 16 & 13 & $13 / 100 \%$ \\
\hline Cohort 2 (2017) & 54 & 36 & $\begin{array}{l}25(5 \text { were peer mentors } \\
\text { from Cohort } 1)\end{array}$ & $\begin{array}{l}20 / 100 \% \text { (not } \\
\text { counting peer } \\
\text { mentors) }\end{array}$ \\
\hline Cohort 3 (2018) & 36 & 30 & 24 & $22 / 92 \%$ \\
\hline Cohort 4 (2019): & 52 & 23 & 20 & $18 / 90 \%$ \\
\hline Rural Cohort (2019) & 10 & 10 & 5 & 82 \\
\hline Totals & 169 & 115 & $4 / 80 \%$ & $77 / 94 \%$ \\
\hline
\end{tabular}

\section{Overall Program Outcomes}

Seventy-seven students certified as HSCHWs (plus five students certified as peer mentor HSCHWs) (Table 3). Thirty-six community/school-based project ideas were generated. Out of those ideas, 16 health intervention projects were developed and presented to community representatives including the following topics: sexually transmitted disease prevention in teens, teen suicide, tobacco use, teen homicide, high cholesterol, unintentional injuries, fitness awareness, healthy eating, stress awareness, cyberbullying, teen mental health, immigrant health fair, environmental clean-up, self-care for teens, addiction education and peer pressure.

Community partnerships are developed by program staff and enhanced with organizations interested in supporting student training and community projects, including the local high schools, Georgia Department of Public Health, Health
Promotion Action Coalition, A Womban's Place, Genesis Prevention Coalition, Odyssey Family Counseling, Andrew and Walter Young YMCA, and Greening Youth Foundation. Partners provided mentorship, material support, space and/or direct service in support of the student's projects. Also, during the summer of 2016, 13 students presented their work at the 12th Annual National CHW Unity Conference in Atlanta, Georgia.

During all summers there was a 99\% daily attendance rate. Students completed shadowing activities with primary care physicians at the Morehouse Healthcare Comprehensive Family Healthcare Clinic, with a full-time $\mathrm{CHW}$ in the HUD/Atlanta Housing Authority Choice Neighborhood project, and with community partners Odyssey Family Counseling Center, Walgreen's community pharmacies, Metro Atlanta Urban Farms, and Greening Youth Foundation. They were able to experience the importance of medical and non-medical individuals and teams in achieving 
optimal health. In addition, over 300 individuals (family and community members) were provided with initial screening, a plan for health improvement, and monthly monitoring. The preliminary program outcomes are strong and support the case for program expansion.

\section{DISCUSSION}

Overall, the HSCHW program is a program designed to improve population health and health equity in underserved communities. The HSCHW program exemplifies the engagement of multidisciplinary education and community partners to develop, implement, evaluate and disseminate an innovative approach to community health.

\section{Beneficial Impacts (Or Benefits to Community Health)}

The HSCHW program has had a tremendous impact on the youth themselves, their families, and the communities in which they live. One way the impact of this program has been demonstrated is through the family and community health monitoring component. Through the health monitoring component, students were able to encourage their households to engage in healthier behaviors, be encouraged to take prescribed medications, and in one documented instance, identify a parent with elevated blood pressure. Students also had an opportunity to monitor WellCare (health plans) members with diabetes. These WellCare subscribers were supported by the HSCHWs to pay more attention to the care of their illness, understand the importance of proper nutrition to the management of their illness and the importance of keeping doctor's appointments to sustain better health outcomes.

Other impacts of the HSCHW program on the community have been demonstrated in the successful implementation of community projects that promoted walking and physical activity for cholesterol reduction, smoking cessation among teens, suicide prevention and education for youth, health eating and cooking demonstrations, a diabetes awareness health fair and stress reduction activities. Through the design and development of the projects, students learned about community health and the importance of collaboration and communication. Even in an environment of limited direct interaction (COVID-19), students were successfully able to reformat their projects to be delivered through social media, video, and community-centered newsletters. The use of virtual space has facilitated the expansion of their reach beyond those they interact with on a daily basis at home and in school to the larger community.

\section{Limitations (Or Challenges)}

When the program was initiated and in subsequent discussions, it was assumed the challenge would be with the youth and their ability to handle the material. That has not been the case. The consistent challenge has been with the students applying what they have learned via monitoring and community projects through sustainable partnerships. Many times, the students may not have had a sufficient number of engaged family members. The attempt was made to supplement with additional monitoring community participants with our community partners but have found that can be challenging while maintaining a safe environment for our students. A similar challenge is with the community partners. The students themselves are often motivated, and when guided, intentional in their responsibilities. On occasion, community partners needed encouragement to work with the HSCHW participants. Most likely due to some partners' employees not expecting an adolescent making requests for services, or resistant to engaging persons of that age.

\section{Next Steps}

The next goal of the program is to assess the impact of the program longitudinally. We know of the immediate outcomes among our student participants. We are developing the necessary processes (e.g. Family Education Rights and Privacy Act, FERPA) to follow the students' educational outcomes while in high school and for those who have pursued a college education. We know the students who have enrolled in college and expressed interest in pursuing a science or health-related degree. We now need to determine their success in those pursuits and initial professional employment.

In addition, it would be beneficial to assess the impact on the participating households. The plan is to conduct focus groups with parents/family members on how their child's participation has impacted them and even the perception of their child academically, maturity, and expectations. And for high schools that have consistent student participation, it may be worthwhile to have a similar discussion with the school leadership, science teachers, or counselors on the impact it has had with the institution.

\section{Adverse effects}

The program itself did not demonstrate any adverse effects, However, one issue that did become apparent and that was how social determinants affect student participants. Many of the students or their family members had mental health challenges, experienced periods of homelessness or, were considered the head of their households financially, etc.; To assist participants and provide needed psychosocial support, a Masters of Social Work (MSW) student intern from Clark Atlanta School of Social Work was recruited in the summer of 2018 and school year 2018-19 to work in conjunction with Odyssey Family Counseling, a community-based behavioral health agency. The addition of an MSW intern has been of such benefit (increased student engagement, improved retention, early identification and resolution of student's personal challenges), it is now incorporated in the program design.

\section{CONCLUSIONS}

One of the ways we know that the HSCHW program is working for its intended audience is feedback from the 
population of interest. The mother of one of the trained HSCHW students wrote:

"I want to personally thank you for offering this program. I didn't think I would be directly impacted by my son participating, but last month he saved my life. During his September assessment, (Student name) received an extremely high blood pressure reading for me. I ended up going to urgent care. His assessment also led me to find a primary care physician which I didn't have. In summary, I was diagnosed with hypertension. I tell my son frequently that he saved my life because I had no clue I was walking around with high blood pressure, the silent killer. I really thought my headaches were a result of stress. A month later, I feel so much better. Thank you again for offering this program and having the patience to equip these teenagers with the necessary tools to really have impact and improve the health of their communities."

A feature story in the Spring 2020 issue of YES! Magazine highlights this families' story and other HSCHW program successes. (Jarvis, 2020)

Based on the World Health Organization's prediction of the healthcare workers shortage and the training of CHWs as an important strategy to help alleviate that shortage, trained high school students can be that future healthcare workforce as well assist families and communities with attaining better health outcomes now. We have a 5-year plan for scale, replication, and sustainability; which include the sale of the developed online curriculum to interested parties. There are currently plans to address the healthcare shortages (Nelson, 2016) in these strategic locations: the current Metro Atlanta urban program, the rural Georgia program, a national and an international program in Ghana \& Tanzania.

In addition, an alumni network was developed to engage students who have successfully completed the 1-year program. Upon completion, students are automatically placed into the HSCHW Alumni Network, providing them with community, resources, connection to Morehouse School of Medicine, and pertinent information regarding their future.

This group of youth is made up of future medical and public health professionals, scientists, political officials, and more. The HSCHW Alumni Network provides a unique opportunity for program participants to:

- Share the outcomes of their school or community-based health initiatives and projects with other students

- Learn about health disparities and community issues other young people experience in other cities

- Collaborate on social media health campaigns and public health initiatives
- Share their stories post-program, including their journey to college, continuation of high school, obtaining a job

- Remain updated on additional pipeline programs, summer programs, internships, scholarships, and job openings

- Feel a sense of community with youth around the world who share like-minded interests

\section{IMPLICATIONS FOR PUBLIC HEALTH}

All high school students should be trained to monitor their own health and that of their family members and to provide health programming and health literacy support to their communities. High School Community Health Workers are bridges to health equity. Interested parties who would like to replicate this program, are interested in purchasing the online curriculum or desire tips on successfully engaging youth in community health improvement may be interested in our Training of Trainers (TOT) workshop held quarterly. Please visit our website for more information. https://www.msm.edu/Education/PipelinePrograms/chw-onl ine.php

\section{Acknowledgements}

Mr. Ashley Davis, Georgia Department of Public Health, United Way of Atlanta, WellCare of Georgia, Fulton/Dekalb Hospital Authority, Atlanta Regional Collaborative for Health Improvement (ARCHI), McClarin Success Academy, Tri-Cities High School, Odyssey Family Counseling Center, Greening Youth, MSM CFHC (Comprehensive Family Healthcare), United Healthcare Foundation, Grady Healthcare, Piedmont Healthcare.

\section{References}

Akintobi, T.H., Wilkerson, D.E., Rodgers, K., Escoffery, C., Haardörfer, R., \& Kegler, M. (2016). Assessment of the building collaborative research capacity model: Bridging the community-academic researcher divide. Journal of Georgia Public Health Association. 6(2):123-132,

American Public Health Association (APHA, 2010). Community health worker Definition. Accessed February 1, 2020. https://www.apha.org/policies-and-advocacy/public-health-polic y-statements/policy-database/2014/07/09/14/19/support-for-com munity-health-workers-to-increase-health-access-and-to-reducehealth-inequities

American Public Health Association (APHA). Community Health Workers. Accessed November 6, 2017.

http://www.apha.org/apha-communities/member-sections/comm unity-health-workers

ARCHI Playbook. archicollaborative.org. (August 2017). Accessed November 16, 2017.

http://archicollaborative.org/wp-content/uploads/2017/09/ARCH I_Playbook_2017.pdf

Boekeloo, B.O., Jones, C., Bhagat, K., Siddiqui, J., \& Wang, M.Q. (2015). The role of intrinsic motivation in the pursuit of health science-related careers among youth from underrepresented low socioeconomic populations. Journal of Urban Health. (5):980-994. doi: 10.1007/s11524-015-9987-7

Brunie, A, Wamala-Mucheri, P., Otterness, C., Akol, A., Chen. M., Bufumbo, L., \& Weaver, M. (2014). Keeping community health workers in Uganda motivated: key challenges, facilitators, and preferred program inputs. Global Health Science and Practice. 2(1):103-116. doi: 10.9745/GHSP-D-13-00140 
Design Kit. What is human-centered design? designkit.org. Accessed November 6, 2017.

http://www.designkit.org/human-centered-design

Galiatsatos, P., Sundar, S., Qureshi, A., Ooi, G., Teague, P., \& Hale, W.D. (2016). Health promotion in the community: impact of faith-based lay health educators in urban neighborhoods. Journal of Religion and Health. 2016;55:1089-1096. doi: 10.1007/s10943-016-0206-y

Grover, A. (May 6, 2016). Strategies to address physician shortages in rural and underserved communities. Association of American Medical Colleges. Accessed November 6, 2017. https://www.aamc.org/download/431632/data/20150506_ruralan dunderservedbriefingatugroverppt.pdf

Fox, S. \& Duggan, M. (2013). Health online. Pew Research Center - Internet and Technology. Accessed June 14, 2020. https://www.pewresearch.org/internet/2013/01/15/health-online2013/

Fox, S. \& Duggan, M. (2013). Information triage. Pew Research Center - Internet and Technology. Accessed June 14, 2020. https://www.pewresearch.org/internet/2013/01/15/information-tr iage/

Health Resources and Services Administration, National Center for Health Workforce Analysis. (2017). Sex, race, and ethnic diversity of U.S. health occupations (2011-2015). U.S. Department of Health and Human Services. Rockville, MD.

Jack, H.E., Arabadjis, S.D., Sun, L., Sullivan, E.E., Phillips, R.S. (2017). Impact of community health workers on use of healthcare services in the United States: a systematic review. Journal of General Internal Medicine. 32(3):325-344. doi: 10.1007/s11606-016-3922-9

Kanea, E.P., Collinsworth, A.W., Schmidt, K.L., Brown, R.M., Snead, C.A., Barnes, S.A., Fleming, N.S., \& Walton, J.W. (2016). Improving diabetes care and outcomes with community health workers. Family Practice. 3(5):523-528. https://doi.org/10.1093/fampra/cmw055

Kangovi, S., Carter, T., Charles, D., Smith, R.A., Glanz, K., \& Grande, D. (2016). Toward a scalable, patient-centered community health worker model: adapting the IMPaCT intervention for use in the outpatient setting. Population Health Management. 19(6):380-388.

Lauver, L.S., Swan, B.A., West, M.M., Zuwosky, K., Powell, P., Frisby, T., Neyhard, S., \& Marsella, A. (2011). Kids into health careers: a rural initiative. Journal of Rural Health. 27(1):114-121. doi: 10.1111/j.1748-0361.2010.00316.x

Levitt, N.S., Puoane, T., Denman, C.A., Abrahams-Gessel, S., Surka, S., Mendoza, C., Khanam, M., Alam, S., \& Gaziano, T.A. 2015. Referral outcomes of individuals identified at high risk of cardiovascular disease by community health workers in Bangladesh, Guatemala, Mexico, and South Africa. Global Health Action 8 (1): 10.3402/gha.v8.26318. doi:10.3402/gha.v8.26318. http://dx.doi.org/10.3402/gha.v8.26318

Martin, M.A., Rothschild, S.K., Lynch, E., Kaufer Christoffel, K., Militza M. Pagán, M.M., Rodriguez, J.L., Barnes, A., Karavolos, K., Diaz, A., Hoffman, L.M., Plata, D., \& Villalpando, S. (2016). Addressing asthma and obesity in children with community health workers: proof-of-concept intervention development. BMC Pediatrics. 16:198. doi: 10.1186/s12887-016-0745-0

Morehouse School of Medicine. (2015). Homepage - Vision statement - 40th Anniversary. Accessed November 6, 2017. http://www.msm.edu/about_us/

Morehouse School of Medicine. Georgia Clinical and Translational Science Alliance (CTSA). (2015).

http://georgiactsa.org/news-and-events/news/2015/community/c ommunity-health-worker/index.html
Morehouse School of Medicine. Georgia Clinical and Translational Science Award (CTSA).

(2015).http://www.msm.edu/RSSFeedArticles/April2015/CFHC CommunityOpenHouse.php

Morehouse School of Medicine. Pipeline Programs - Summer 2017. Accessed November 6, 2017.

http://www.msm.edu/Education/PipelinePrograms/summerprogr ams.php

Morehouse School of Medicine. Prevention Research Center. Accessed February 19, 2020.

http://www.msm.edu/Research/research_centersandinstitutes/PR C/index.php

Morgan, A.U., Grande, D.T., Carter, T., Long, J.A., \& Kangovi, S. (2016). Penn Center for Community Health Workers: step-by-step approach to sustain an evidence-based community health worker intervention at an academic medical center. American Journal of Public Health. 106(11):1958-1960. doi: 10.2105/AJPH.2016.303366

Murayama, H., Spencer, M.S., Sinco, B.R., Palmisano, G., \& Kieffer, E.C. (2016). Does racial/ethnic identity influence the effectiveness of a community health worker intervention for African American and Latino adults with Type 2 diabetes? Health Education and Behavior. 44(3):485-493.

Nelson, G. D. (2016). The two Georgias: Disparities in rural health and healthcare Journal of the Georgia Public Health Association. 5(4):294-296. doi: 10.21663/jgpha.5.401

Rashied-Henry, K., Fraser-White, M., Roberts, C.B., Wilson, T.E., Morgan ,R., Brown, H., Shaw, R,, Jean-Louis, G., Graham, Y.J., Brown, C., \& Browne, R. (2012). Engaging minority high school students as health disparities interns: findings and policy implications of a summer youth pipeline program.. Journal of the National Medical Association. 104(9-10):412-419. DOI: 10.1016/s0027-9684(15)30194-2

Seidman,G. and Atun, R. (2017). Does task shifting yield cost savings and improve efficiency for health systems? a systematic review of evidence from low-income and middle-income countries. Human Resources for Health. 15:29. doi 10.1186/s12960-017-0200-9

Smith, K.W., Bir, A., Freeman, N.L.B., Koethe, B.C., Cohen, J., \& Day, T.J. (2017). Impact of health care delivery system innovations on total cost of care. Health Affairs (Millwood). 36(3):509-515. doi: 10.1377/hlthaff.2016.1308

Tilahun, D., Hanlon, C., Araya, M., Davey, B., Hoekstra, R.A., \& Fekadu, A. (2017). Training needs and perspectives of community health workers in relation to integrating child mental health care into primary health care in a rural setting in sub-Saharan Africa: a mixed methods study. International Journal of Mental Health Systems.11:15. doi: 10.1186/s13033-017-0121-y

United Health Foundation. (December 2019). America's Health Rankings - 30 years. Annual Report. https://www.americashealthrankings.org/

Wallerstein, N., Minkler, M., Carter-Edwards, L., Avila M, \& Sánchez, V. (2015). Improving health through community engagement, community organization, and community building. In: Glanz, K., Rimer ,B.K., \& Viswanath, K., eds. Health Behavior: Theory, Research, and Practice. New York, NY: Wiley.

World Health Organization (WHO). Global health workforce shortage to reach 12.9 million in coming decades. (November 11, 2013). Accessed November 6,

2017.http://www.who.int/mediacentre/news/releases/2013/health -workforce-shortage/en/.

Zulu, J.M., Kinsman, J., Michelo, C., \& Hurtig, A.K. (2014). Hope and despair: community health assistants' experiences of 
working in a rural district in Zambia. Human Resources for

Health. 12:30. doi: 10.1186/1478-4491-12-30

\section{APPENDIX}

Table 1

Training Core Competencies

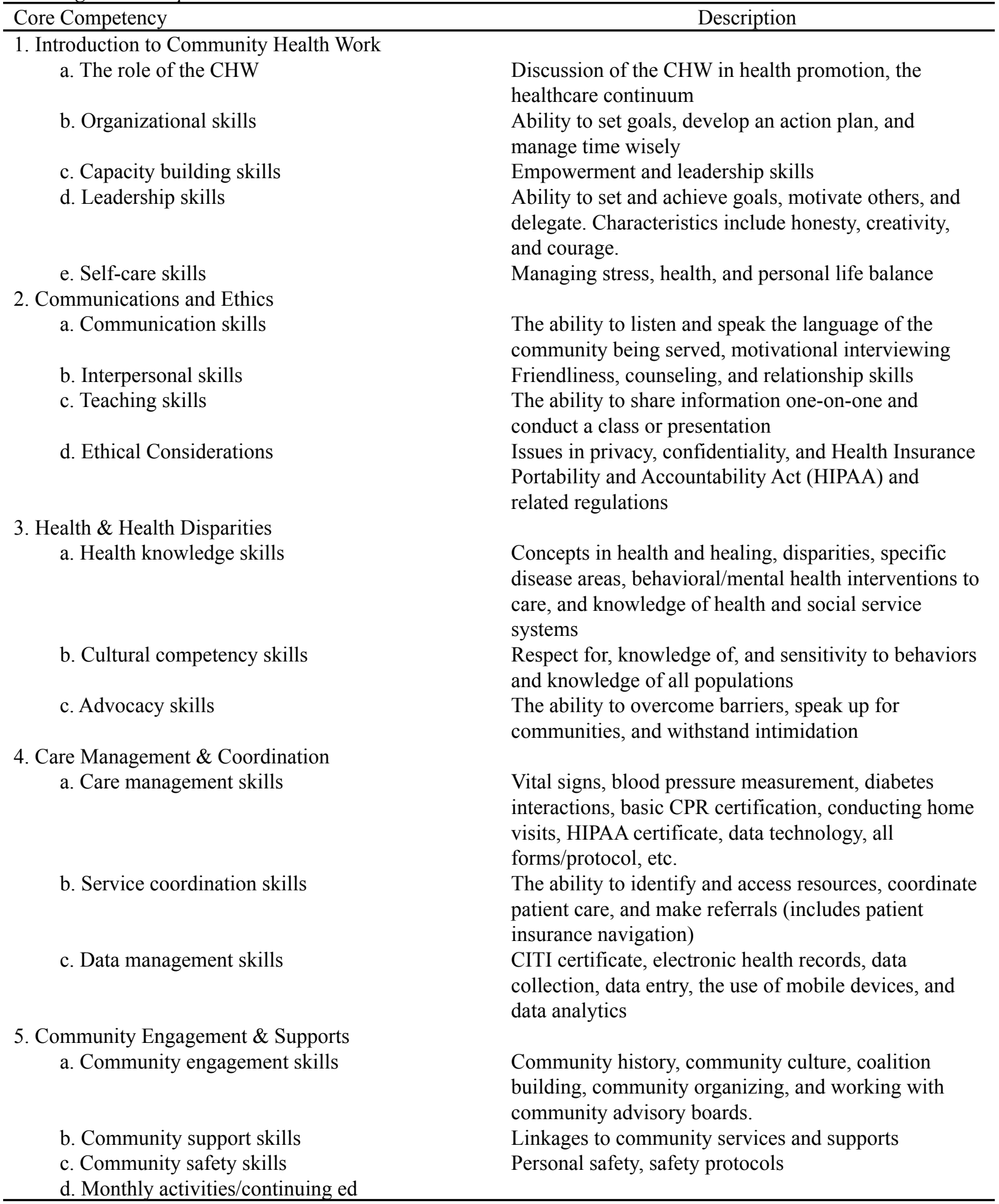

Source: Author 
Table 2

Core Competencies Mapped to Activities and Outcomes

Core Competency Category/Associated

Experiential Activities

Associated Program Goals/Objectives

Skills

Introduction to Community Health Work

The role of the

CHW includes discussion of the CHW Peer-mentors as team leaders

in health promotion, the healthcare

continuum

Organizational skills include the ability to set goals, to develop an

action plan, and to manage time wisely

Capacity building skills include empowerment and leadership skills

Leadership skills include the ability to set and achieve goals, motivate others, and delegate. Some characteristics include honesty, creativity, and courage.

Self-care skills include managing stress, health, and personal life balance

Communication \& Ethics

Communication skills include the

ability to listen and speak the language

of the community being served,

motivational interviewing

Interpersonal skills include

friendliness, counseling, and

relationships skills.

Teaching skills include the ability to

share information one-on-one and

conduct a class or presentation

Ethical considerations include issues

in privacy, confidentiality, and Health

Insurance Portability and

Accountability Act (HIPAA) and

related regulations.

Health \& Health Disparities

Health knowledge skills include concepts in health and healing, disparities, specific disease areas, behavioral/mental health interventions to care, and knowledge of health and social service systems

Cultural competency skills include respect for, knowledge of, and sensitivity to behaviors and knowledge of all populations

Advocacy skills include the ability to overcome barriers, speak up for communities, and withstand intimidation
Students as community leaders

Demonstration of learned self-care

activities (e.g., yoga, meditation, eating habits, exercises)

Motivational interviewing

of patients/community members

Taking vital signs

Motivational interviewing

Intervention design \& development
Pipeline for health career fields

Support and promote the CHW field

Mentorship for underserved students

Improve healthy behaviors

Promote health education \& health literacy
Foster care coordination for family \& community members

Promote health education \& health

literacy

Improve healthy behaviors

Care Management \& Coordination

(C) Arletha D. Williams-Livingston, Christopher E. Ervin, and Gail G. McCray. Originally published in jGPHA (http://www.gapha.org/igpha/)

July 24, 2020. This is an open-access article distributed under the terms of the Creative Commons Attribution Non-Commercial No-Derivatives License (http://creativecommons.org/licenses/by/4.0/), which permits unrestricted use, distribution, and reproduction in any medium, provided the original work ("first published in the Journal of the Georgia Public Health Association...") is properly cited with original URL and bibliographic citation information. The complete bibliographic information, a link to the original publication on http://www.gapha.jgpha.org/, as well as this copyright and license information must be included. 